Article

\title{
Climate Data Records from Meteosat First Generation Part I: Simulation of Accurate Top-of-Atmosphere Spectral Radiance over Pseudo-Invariant Calibration Sites for the Retrieval of the In-Flight Visible Spectral Response
}

\author{
Yves M. Govaerts ${ }^{1, *(1)}$, Frank Rüthrich ${ }^{2}$, Viju O. John ${ }^{2}$ (i) and Ralf Quast ${ }^{3}$ (i) \\ 1 Rayference, 1030 Brussels, Belgium \\ 2 Eumetsat, D-64295 Darmstadt, Germany; Frank.Ruethrich@eumetsat.int (F.R.); \\ Viju.John@eumetsat.int (V.O.J.) \\ 3 FastOpt, 22767 Hamburg, Germany; ralf.quast@fastopt.de \\ * Correspondence: yves.govaerts@rayference.eu
}

Received: 5 November 2018; Accepted: 3 December 2018; Published: 5 December 2018

check for updates

\begin{abstract}
Meteosat First-Generation satellites have acquired more than 30 years of observations that could potentially be used for the generation of a Climate Data Record. The availability of harmonized and accurate a Fundamental Climate Data Record is a prerequisite to such generation. Meteosat Visible and Infrared Imager radiometers suffer from inaccurate pre-launch spectral function characterization and spectral ageing constitutes a serious limitation to achieve such prerequisite. A new method was developed for the retrieval of the pre-launch instrument spectral function and its ageing. This recovery method relies on accurately simulated top-of-atmosphere spectral radiances matching observed digital count values. This paper describes how these spectral radiances are simulated over pseudo-invariant targets such as open ocean, deep convective clouds and bright desert surface. The radiative properties of these targets are described with a limited number of parameters of known uncertainty. Typically, a single top-of-atmosphere radiance spectrum can be simulated with an estimated uncertainty of about $5 \%$. The independent evaluation of the simulated radiance accuracy is also addressed in this paper. It includes two aspects: the comparison with narrow-band well-calibrated radiometers and a spectral consistency analysis using SEVIRI/HRVIS band on board Meteosat Second Generation which was accurately characterized pre-launch. On average, the accuracy of these simulated spectral radiances is estimated to be about $\pm 2 \%$.
\end{abstract}

Keywords: climate data records; calibration; sensor spectral function; radiative transfer modelling; Meteosat Visible and Infrared Imager (MVIRI)

\section{Introduction}

Meteosat Visible and Infrared Imager (MVIRI) on board Meteosat First-Generation (MFG) satellites (1977-2017) acquires radiances every $30 \mathrm{~min}$ in a single large spectral band, referred to as the visible (VIS) band, ranging approximately from $0.4 \mu \mathrm{m}$ up to $1.1 \mu \mathrm{m}$. The primary objective of the MFG program was the acquisition of earth atmosphere images and their near-real-time dissemination to the meteorological user's community. Hence, requirements on the accuracy of the pre-launch Sensor Response Function (SRF) characterization were rather loose. Consequently, anomalies and inconsistencies in the generation of Fundamental Climate Data Record (FCDR) and Climate Data Record (CDR) from MFG MVIRI/VIS band data have already been reported. For instance, the 
MVIRI/VIS band calibration on board Meteosat- 5 and -6 based on the pre-launch SRF characterization provided inconsistent results [1]. Significantly different calibration values were obtained over sea and bright desert Pseudo-Invariant Calibration Sites (PICSs) that was attributed to an issue with the SRF characterization of these two instruments. As a consequence of this lack of accurate pre-launch SRF characterization, the surface albedo CDR generated for the entire MFG archive exhibits temporal inconsistencies [2]. In addition to these pre-launch characterization limitations, degradations of the spectral response shape have also been pointed out in previous studies [3]. This spectral ageing process results from a faster degradation in the blue than in the near-infrared part of the VIS band [4]. Hence calibration coefficients derived over sea surface or bright desert do not exhibit the same temporal degradation rate when derived using the pre-launch SRF value for the entire mission lifetime.

Despite all these issues, the potential value of MVIRI data for climate monitoring should not be underestimated [5]. During the late 1970s and early 1980s, space-borne observations of the Earth were very scarce, essentially limited to geostationary meteorological observations and a few polar platforms. The generation of a consistent FCDR from the MFG archive requires thus substantial but worthwhile efforts to improve the characterization of the measurement uncertainty and a post-launch reconstruction of the original SRFs, including their spectral ageing. The Fidelity and Uncertainty in CDRs from Earth Observation (FIDUCEO) research project aims to improve the SRF characterization and properly quantify the uncertainty to facilitate the creation of optimal consistent long-term data records. The generation of consistent MFG FCDR with fully traceable uncertainty is one of the main objectives of this project. In this context, a new reverse engineering method was developed for the recovery of the MVIRI/VIS spectral response and its uncertainty accounting for the temporal ageing effects [6]. This method requires essentially two pieces of information: the Digital Count (DC) value of selected pixels over PICSs and the corresponding simulated Top-Of-Atmosphere (TOA) spectral radiance in the MVIRI/VIS band. For each piece of information, it is important to accurately identify and estimate all possible sources of uncertainties. Pixel radiative properties located over PICS targets can be characterized with a limited number of parameters of known uncertainty. Additionally, the spectral signature of these different targets should be significantly different to make the SRF retrieval possible. Three different types of PICS are used for that purpose: bright desert, open ocean and Deep Convective Cloud (DCC).

The objectives of this paper are to (i) describe the pixel identification mechanism over the selected PICS, (ii) simulate the corresponding TOA spectral radiance and (iii) evaluate the accuracy of these simulations. Open ocean and bright desert targets have already been used for the calibration of the MVIRI/VIS band [7]. The same selection method is reused here. A specific method was developed in the framework of this study for the identification of DCC pixels. Section 3 summarizes the pixel identification methods over these three types of targets. TOA spectral radiances and associated uncertainties are simulated with an accurate Radiative Transfer Model (RTM) (Section 4). Finally, the independent evaluation of these simulations' accuracy is addressed in Section 5.

\section{Background}

MFG image row and column acquisition results from a combination of the main mirror rotation (row) and satellite spin (column). The nominal sub-satellite point of the MFG mission is $0^{\circ}$ longitude and is referred to as the Zero Degree Mission (ZDM). Since 1998 near the end of their operational lifetime Meteosat satellites are moved over the Indian Ocean originally in support to the INDian Ocean EXperiment (INDOEX) [8]. The VIS band of MVIRI is composed of two detectors scanning simultaneously two lines of pixels plus two backup detectors in case of failure of the two operational ones. An offset voltage of about $100 \mathrm{mV}$ is added to the detector electronics that corresponds to a mean offset value of about 5 counts when the instrument is pointing to space. Please note that this offset voltage was implemented for the first time on board Meteosat 4 when the digitalization of the VIS band signal switched from 6 to 8 bits. The total spectral response of a VIS band detector is essentially determined by the reflectance and transmittance properties of the telescope optics and the silicon 
photo-diode detector as there is no spectral filter. There is no onboard device for the calibration of the VIS band. Figure 1 shows the shape of the Meteosat-7 MVIRI/VIS band pre-launch SRF together with the major molecular absorption features in that spectral region.

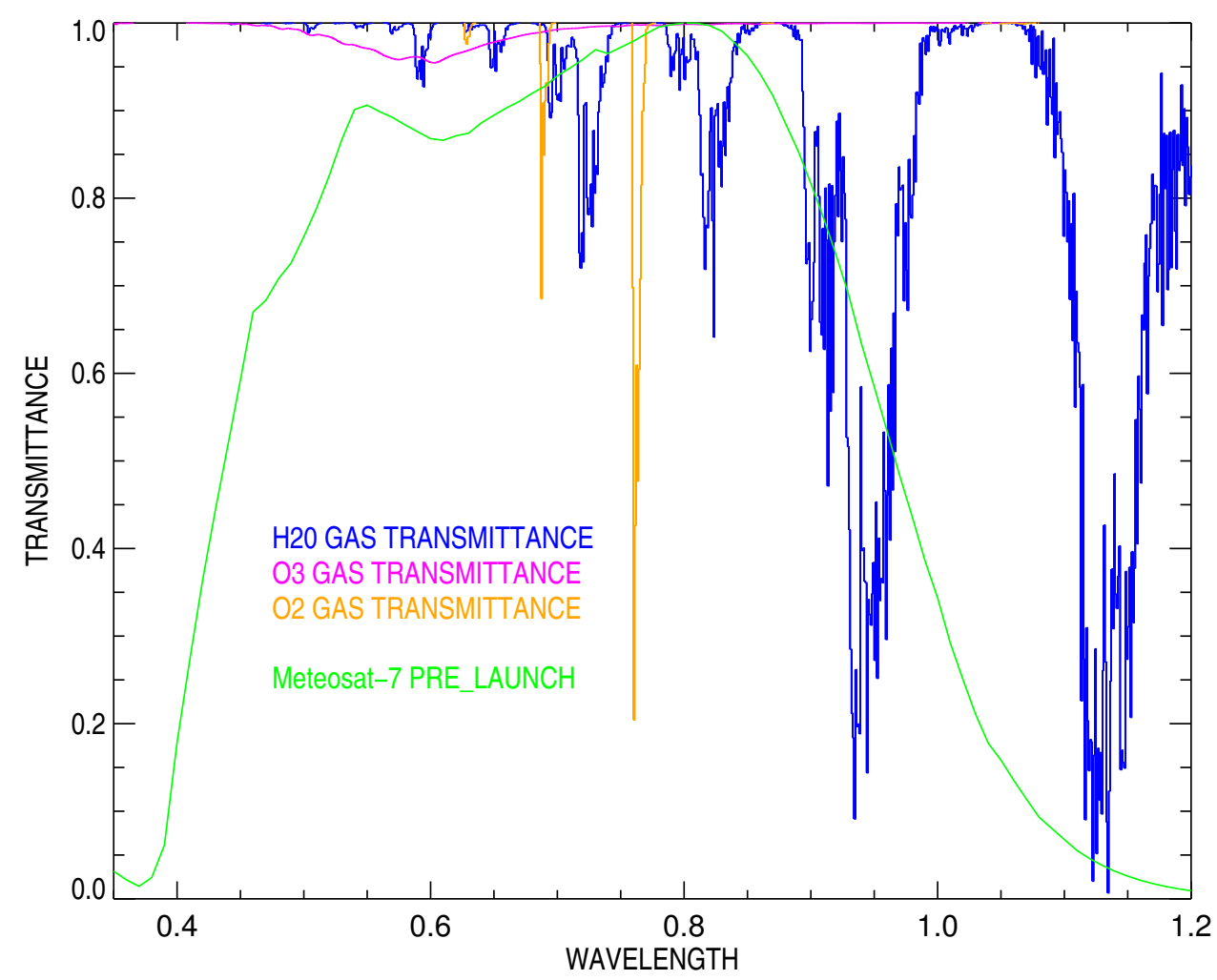

Figure 1. Molecular transmittance in the MVIRI/VIS band spectral range for the following gases: water vapor (blue), ozone (magenta) and oxygen (orange). The green line shows the pre-launch SRF of MVIRI/VIS band on board Meteosat-7. Wavelength is expressed in $\mu \mathrm{m}$.

The routine vicarious calibration of the MVIRI/VIS band relies on the SEVIRI Solar Channel Calibration (SSCC) algorithm operated at EUMETSAT [9]. This algorithm accumulates MVIRI observations over 5 days over a series of bright desert PICSs [10] to derive a calibration coefficient and its associated uncertainty. A set of consistency tests, including calibration over sea targets, is also performed to disregard suspicious calibration coefficient estimation [11]. This method relies on the pre-launch characterization of the MVIRI/VIS band SRF without accounting for its spectral ageing [7]. Consequently, calibration coefficients derived over sea surface or bright desert do not exhibit the same degradation rate.

The purpose of the MVIRI/VIS band SRF retrieval method is to provide the in-flight SRF characterization and to monitor its spectral ageing. This retrieval method relies on two major sources of information. First, the MVIRI/VIS Digital Count (DC) values and associated uncertainties acquired over selected PICSs. Three type of pseudo-invariant targets are used for that purpose: (i) a bright desert target (Libya-4); (ii) open ocean with low aerosol load and (iii) tropical DCC. The former two target types were already included in SSCC and their identification in clear-sky conditions relies on this algorithm. The second piece of information required by the SRF retrieval method is the corresponding TOA spectral radiance at the telescope entrance. This spectral radiance $L\left(\Omega, \lambda, t, l ; q_{j}\right)$ depends on the viewing and illumination zenith and azimuth angles noted in a condensed way as $\Omega$, the wavelength $\lambda$, the acquisition time $t$, the geographical location $l$ and finally the $N_{q}$ state variables $q_{j}$ with $j \in\left[1, N_{q}\right]$ defining the surface and atmosphere radiative properties listed in Table 1 . The top panel of Figure 2 illustrates TOA spectral radiance simulated over bright desert, open ocean and DCC in the Meteosat 
VIS band spectral interval. Optical properties of the selected targets are assumed almost invariant so that a limited number of parameters can be used for their characterization. Only possible changes in atmospheric composition are expected to take place which can be documented with the European Centre for Medium-Range Weather Forecasts (ECMWF) data [12].

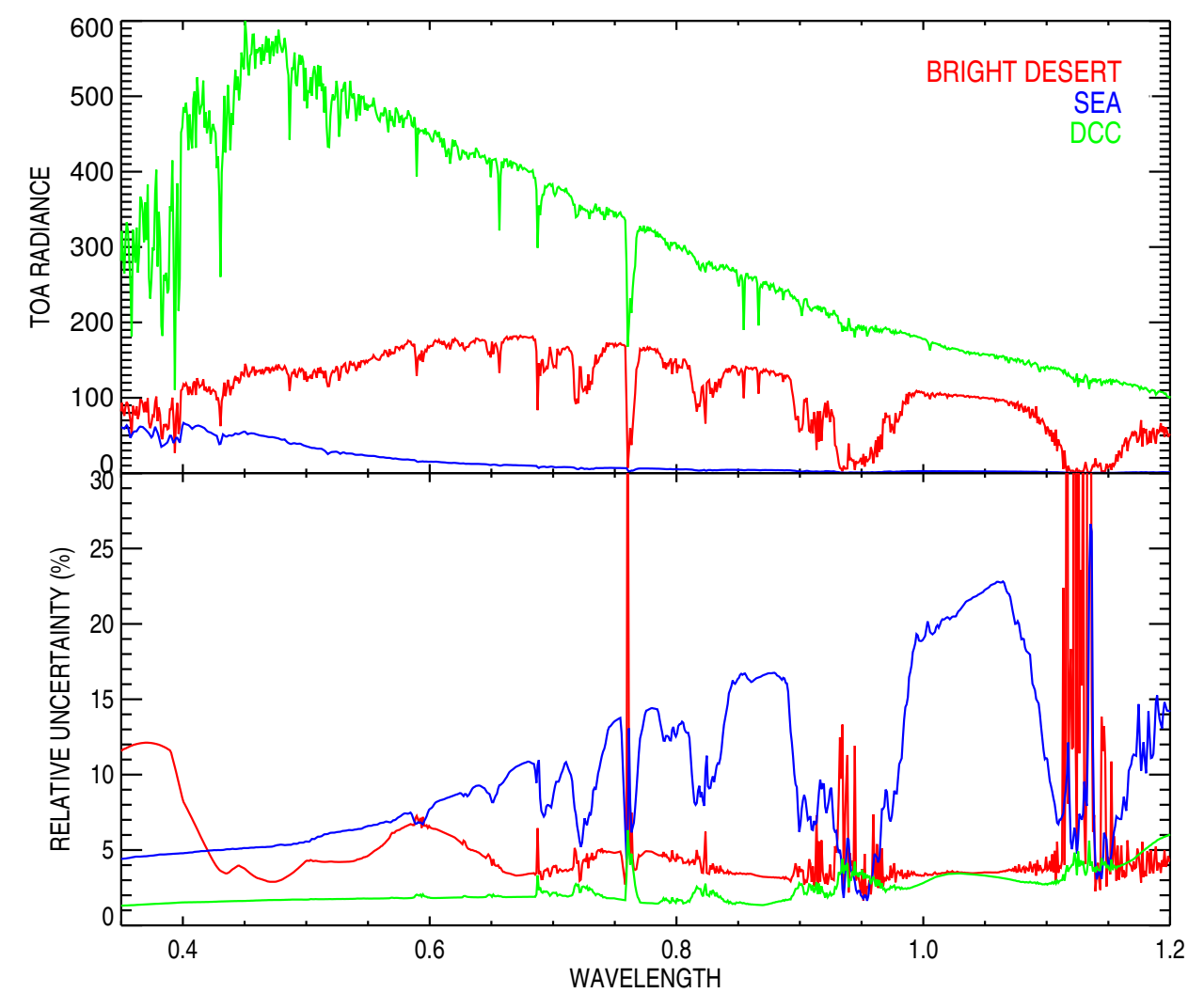

Figure 2. Top panel: Example of simulated TOA spectral radiances $L(\lambda)$ in $\mathrm{Wm}^{-2} \mathrm{sr}^{-1} \mu \mathrm{m}^{-1}$ over bright desert (red), sea (blue) and DCC (green)as a function of the wavelength in $\mu \mathrm{m}$ in the Meteosat VIS band spectral interval on 17 June 2005. Bottom panel: Estimated relative uncertainty in percent.

The calibration coefficient $a(t, l)$ derived at time $t$ and location $l$ is expressed as a function of the spectral radiance $L\left(\Omega, \lambda, t, l ; q_{j}\right)$ convoluted with the SRF $\phi(\lambda, t)$ and the matching DC value $C(t, l)$ with

$$
a(t, l)=\frac{\int_{\lambda} L\left(\Omega, \lambda, t, l ; q_{j}\right) \phi(\lambda, t) \mathrm{d} \lambda}{C(t, l)-C_{0}(t)}
$$

where $C_{0}(t)$ is the DC offset value. Assuming that it is possible to simulate accurately the actual TOA spectral radiance $L\left(\Omega, \lambda, t, l ; q_{j}\right)$ in Equation (1), the magnitude of the coefficients $a(t, l)$ over the different targets should be the same, whatever the spectral shape of the incoming signal. When it is not the case, three possible reasons could explain such inconsistency. Firstly, the difference can be due to a non-linear radiometer response to the incoming radiance intensity. The pre-launch characterization of Meteosat-7 showed that any possible non-linearities are smaller than the digitalization level [13]. Secondly, inconsistencies could occur when simulated spectral radiances $L\left(\Omega, \lambda, t, l ; q_{j}\right)$ are erroneous. The independent accuracy evaluation of these simulated spectral radiances is addressed in Section 5. Finally, possible discrepancies could be explained by the use of erroneous SRF values as already stressed in previous studies [1,3]. It is, therefore, the most likely explanation if the accuracy of $L\left(\Omega, \lambda, t, l ; q_{j}\right)$ can be demonstrated. The possibility to perform a post-launch recovery of $\phi(\lambda, t)$ requires therefore access to accurate TOA spectral radiances over the selected PICSs within the MVIRI/VIS band spectral range. The overall SRF retrieval process within the FIDUCEO project includes the following three main steps: 
1. Pseudo-invariant pixel identification and simulation For each target type, pixels corresponding to the identification criteria described in Section 3 are extracted in the processed MVIRI images. The mean DC value over the selected area is estimated from the so-called RECT2LP MFG native format [14] were the North and South detector values have already been equalized and georectified to the geostationary reference grid [15]. The simulation of the TOA spectral radiances is described in Section 5 and their accuracy evaluation in Section 4.

2. SRF retrieval The MVIRI/VIS band SRF and its spectral degradation is estimated from the extracted DC values and simulated spectral radiances [6].

3. FCDR generation and evaluation. TOA reflectance with associated uncertainty is the main outcome of the MVIRI/VIS band FCDR [16]. Geometry of illumination and observation and all sources of uncertainties are also included. It constitutes a major improvement with respect to the current MVIRI file format that does not include these ancillary values [17].

This paper describes the first step of this process. Steps 2 and 3 are described in companion papers in this issue $[6,16]$.

\section{Identification of Pseudo-Invariant Pixels}

\subsection{Bright Desert}

Libya-4, a Committee on Earth Observation Satellites (CEOS) calibration site, was chosen as bright desert calibration site. It is in the Great Sand Sea and it is one of the most important bright desert CEOS PICS by its size and radiometric stability [10]. This site is intensively used for radiometer drift monitoring, sensor inter-calibration and as an absolute calibration reference based on simulated TOA radiance traceable to SI standard. Libya-4 morphology is composed of oriented sand dunes shaped by dominant winds [18]. It is centered at $28.55^{\circ} \mathrm{N}$ and $23.39^{\circ} \mathrm{E}$ for a spatial extension of about $1^{\circ} \times 1^{\circ}$ or about $100 \times 100 \mathrm{~km}$. Surface and atmospheric radiative properties were accurately characterized [19]. Cloud and sand storm cases are identified by analyzing daily variations of the observed DC values. Clear-sky pixel detection is performed by fitting a second order polynomial to the daily cycle of observations [7]. Any deviations from this polynomial is interpreted as a cloud contamination, cloud shadow, or sand storm. Observations of that day are disregarded when the remaining number of clear-sky slots is too low after this daily filtering.

\subsection{Open Ocean}

Sea targets are defined by large search areas in which cloud- and aerosol-free potential targets are identified, looking at uniform and very low DC values outside sun-glint regions [7]. This procedure ensures that selected pixels correspond to very low Aerosol Optical Thickness (AOT) situations. Surface wind speed and the total column water vapor are extracted from ECMWF data, and a potential clear-sky target is disregarded when the surface wind speed exceeds $7 \mathrm{~m} / \mathrm{s}$ to avoid the presence of foam on rough sea. Aerosol and cloud free sea targets are selected by the SSCC algorithm within the MVIRI disk over the North and South Atlantic Ocean as well as the Indian Ocean.

\subsection{Deep Convective Cloud}

As calibration over DCC has not yet been included in SSCC, a specific identification method was developed for this study. Whatever the mission sub-satellite point, the latitudinal search area is restricted to $\left[-19^{\circ} \mathrm{S}, 19^{\circ} \mathrm{N}\right]$. Different longitudinal search areas are defined for the identification of DCC pixels over land and sea. ZDM search areas run from $1^{\circ} \mathrm{W}$ to $28^{\circ} \mathrm{E}$ over land and $12^{\circ} \mathrm{W}$ to $30^{\circ} \mathrm{W}$ over sea. Over the Indian Ocean Data Coverage (IODC) mission, the corresponding search areas run from $13^{\circ} \mathrm{E}$ to $50^{\circ} \mathrm{E}$ over land and $48^{\circ} \mathrm{E}$ to $88^{\circ} \mathrm{E}$ over sea surfaces. Within each of these search areas, a land/sea mask is used to disregard pixels not belonging to the expected surface type. A series of identification tests are applied in these search areas to select potential DCC pixels: 
1. Viewing and illumination zenith angles should be lower than $30^{\circ}$ to minimize DCC reflectance anisotropy effects;

2. The scattering angles should be larger than $5^{\circ}$ to avoid the backscattering direction [20];

3. DCC brightness temperature in the MVIRI/IR band should be smaller than $205 \mathrm{~K}$ [21];

4. A uniformity test is applied on DC values of the thermal and VIS bands. A pixel is identified as DCC if the spatial uniformity of the $5 \times 5$-pixel window centered on that pixel fulfils the following conditions

$$
\frac{\sqrt{\frac{1}{N_{C}-1} \sum_{l=1}^{N_{c}}(C(t, l)-\bar{C}(t))^{2}}}{\bar{C}(t)}<r_{u}
$$

with where $N_{C}$ is the number of pixels within the selected window, $\bar{C}$ is the mean DC value in that window and $r_{u}$ is the threshold value set to 0.02 .

When all these tests are successful, a pixel is considered to be a potential DCC target. The DC value $C(t, l)$ is extracted from the corresponding MVIRI image and the uncertainty $u(C)$ is assumed equal to the standard deviation of the space count as in [7]. An extracted DC $C(t, l)$ is normalized applying the following formula

$$
C_{n}(t, l)=\frac{\pi d_{\odot}^{2}\left(C(t, l)-C_{0}(t)\right)}{\cos \theta_{0}}
$$

where $d_{\odot}^{2}$ is the sun-earth distance in astronomical unit, $\theta_{0}$ the solar zenith angle. All the normalized DC values are accumulated over a running period of 90 days to generate a histogram. Normalized pixels older than 90 days are removed from the histogram unless there are fewer than 1500 remaining pixels. This threshold value ensures a correct statistical distribution of the extracted DCC DC values. A Gaussian distribution is fitted to this histogram and $3 \sigma$ outliers disregarded. All remaining pixels in the histogram are assumed to be DCC pixels.

\section{TOA Spectral Radiance Simulation}

\subsection{Overview}

The objective is to simulate accurate TOA spectral radiance in the MVIRI/VIS band corresponding to the extracted pixels over bright desert, open ocean and DCC with a method that can be applied for the entire MFG processed data, i.e., from 1982 up to early 2017 when Meteosat-7 was decommissioned. As this period covers the eighties and nineties, the parameters $q_{j}$ that characterize the radiative properties of the surface and atmosphere should essentially rely on climatology or reanalysis data, but cannot be derived exclusively from geophysical products such as those derived from the Moderate Resolution Imaging Spectroradiometer (MODIS). Over each type of target, many pixels are processed to reduce the random contribution of the TOA spectral radiance $L$ error. The estimation of the TOA simulated spectral radiance uncertainty $u(L)$ is performed according to the Guide to the Expression of Uncertainty in Measurement recommendations [22]

$$
u(L)=\sqrt{\sum_{j=1}^{N_{q}}\left(\frac{\partial L\left(\Omega, \lambda, t, l, i ; q_{j}\right)}{\partial q_{j}} u\left(q_{j}\right)\right)^{2}+2 \sum_{j=1}^{N_{q}-1} \sum_{k=j+1}^{N_{q}}\left(\frac{\partial L\left(\Omega, \lambda, t, l ; q_{j}\right)}{\partial q_{j}}\right)\left(\frac{\partial L\left(\Omega, \lambda, t, l ; q_{j}\right)}{\partial q_{k}}\right) u\left(q_{i, k}\right)}
$$

where $u\left(q_{j}\right)$ is the parameter $q_{j}$ uncertainty. As in SSCC, the error covariances $u\left(q_{i, k}\right)$ are assumed equal to zero, i.e., the second term of the right-hand part of Equation (4) is neglected. The characterization of the $q_{j}$ values originates from different source of information and are therefore very likely uncorrelated.

\subsection{Bright Desert}

TOA radiance over bright desert is largely dominated by the downward irradiance reflected by the surface which is assumed strictly time-invariant [23]. Surface reflectance properties of Libya-4 were 
taken from a previous study [19]. Aerosol properties assuming non-spherical particles are taken from the same authors. Total column water vapor and ozone concentrations are taken from ECMWF data assuming a mid-summer for the assignment of the atmospheric vertical profile properties. Spectral TOA radiances were simulated with the LibRadTran version 2 RTM [24] which provides accurate gaseous transmittance values with respect to previous versions of this code [25]. Equation (4) was used for the estimation of the uncertainty with the $u\left(q_{j}\right)$ values listed in Table 1.

An example of simulated TOA radiance and associated uncertainty over bright desert is shown in Figure 2 (red line). The effects of the oxygen absorption bands (see Figure 1) around $0.77 \mu \mathrm{m}$ is clearly visible as well as two major water vapor absorption features centered around $0.95 \mu \mathrm{m}$ and $1.15 \mu \mathrm{m}$ respectively. These sharp spectral variations in the TOA spectral radiance provide useful information for the reconstruction of the Near-Infrared (NIR) part of MVIRI/VIS band SRF. As the surface is very bright, uncertainty is dominated by surface reflectance. The relative uncertainty typically varies between 5 to $10 \%$ to the exception of molecular absorption bands due to the very low spectral radiance magnitude in these spectral regions.

Table 1. Values of the model parameters uncertainty $u\left(q_{j}\right)$.

\begin{tabular}{llcc}
\hline Parameter Name & PICS Type & Uncertainty & Reference \\
\hline Surface reflectance & Desert & $5-10 \%$ & {$[19]$} \\
Surface wind speed & Ocean & $10 \%$ & {$[26]$} \\
Surface wind direction & Ocean & $10 \%$ & {$[26]$} \\
Surface pressure & Desert, ocean & $10 \%$ & {$[26]$} \\
Aerosol optical thickness & Desert, ocean & MAX $\{30 \%, 0.02\}$ & {$[7,19]$} \\
Total column water vapor & Desert, ocean & $10 \%$ & {$[26]$} \\
Cloud optical thickness & DCC & 40 & {$[21,27]$} \\
Cloud ice particle radius & DCC & $10 \mu \mathrm{m}$ & {$[21,27]$} \\
\hline
\end{tabular}

\subsection{Open Ocean}

About $80 \%$ to $90 \%$ of the signal observed at the satellite-level in the MVIRI/VIS band is due to the Rayleigh scattering over sea surface. Calibration over open ocean is therefore often referred to as the "Rayleigh" method [28]. Outside the sun-glint observation conditions, ocean surface reflectance only contributes to about 5 to $10 \%$ of the observed signal. Surface reflectance is simulated with the Cox-Munk model [29] where surface wind direction and intensity are taken from ECMWF data. Salinity and pigment concentration are kept constant. A residual AOT of about 0.05 is assumed considering an aerosol maritime type [30]. This background tropospheric aerosol concentration corresponds to a contribution to the total observed signal of about $5 \%$ in the MVIRI/VIS band. The LibRadTran RTM is also used to calculate TOA spectral radiances over sea. Figure 2 (blue line) shows an example of such simulation. As can be seen, most of the TOA radiance contribution occurs below $0.6 \mu \mathrm{m}$. It is, therefore, an ideal target to support the SRF reconstruction in the blue and green part of the MVIRI/VIS band. In that spectral interval, the relative uncertainty is in the range of $5 \%$. Above $0.6 \mu \mathrm{m}$ uncertainty largely exceeds $10 \%$ because of the very low incoming signal magnitude.

Stratospheric aerosol contribution was originally neglected in the SSCC algorithm as typical aerosol concentrations in that part of the atmosphere are usually approximatively at least ten times smaller than tropospheric background aerosol concentrations. However, two major volcanic eruptions that took place in March-April 1982 (El Chichon) and June 1991 (Pinatubo) injected more than $10^{6}$ tons of $\mathrm{SO}_{2}$ in the stratosphere that stayed there for several months (e.g., [31,32]). These eruptions significantly increased stratospheric AOT as can be seen in Figure 3, impacting thereby calibration over open ocean [11]. In the MVIRI/VIS band, an AOT increase of 0.1 in the stratosphere typically corresponds to an increase of about $50 \%$ of the TOA reflectance whereas the same concentration increase in the troposphere translates into a reflectance increase of about $25 \%$. This difference is essentially due to important molecular absorption processes in the lower part of the troposphere due to the presence of water vapor (Figure 1). This example shows that absolute vicarious calibration method 
relying on the so-called Rayleigh method needs to account for possible changes in stratospheric AOT. TOA spectral radiance simulations over sea targets have thus been performed accounting for the presence of stratospheric aerosols using the data set provided by [33]. Over bright desert and DCC pixels, the effects of stratospheric aerosol concentration increases are negligible.

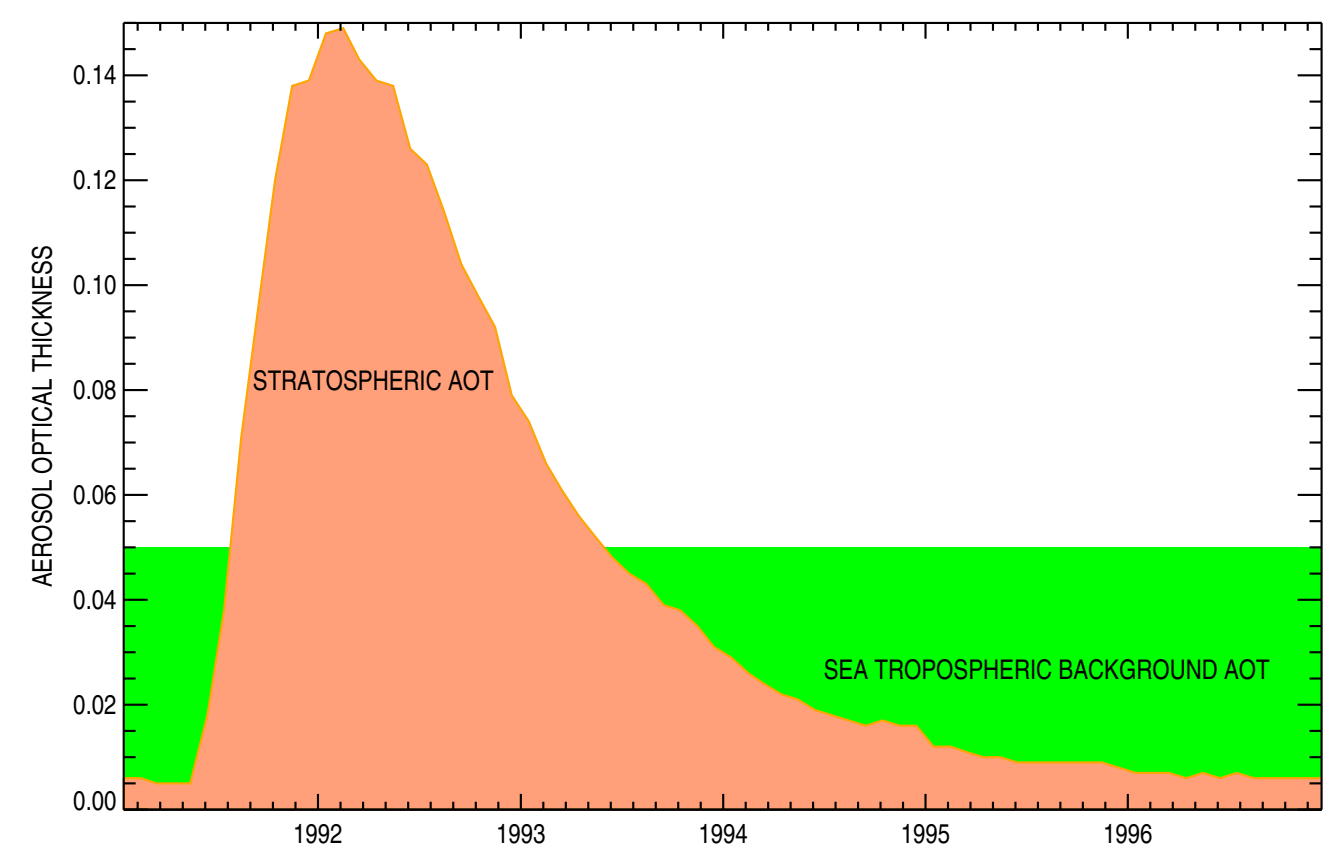

Figure 3. Impact of June 1991 Pinatubo eruption on stratospheric AOT (orange) at $0.55 \mu \mathrm{m}$ after [33]. Typical tropospheric aerosol background optical thickness at $0.55 \mu \mathrm{m}$ over sea within the MVIRI disk is shown in green.

\subsection{Deep Convective Cloud}

The micro-physical properties of the selected DCC pixels are taken from [27]. The lower part of the cloud up to $7 \mathrm{~km}$ is composed of water droplets with a constant effective radius of $10 \mu \mathrm{m}$. Above $7 \mathrm{~km}$, ice particles with a vertical effective radius and optical thickness shown in Figure 4 are assumed. The total Cloud Optical Thickness (COT) typically varies between 70 and 120 [21]. In this study, a mean value of 120 is used over land and 100 over sea. This COT value is distributed along the vertical following the profile displayed in Figure 4 . The identification method described in Section 3.3 was designed to optimize the identification of such type of DCC. Figure 2 (green line) shows an example of simulated spectral radiance with LibRadTran. As tropical DCCs could reach the troposphere-stratosphere boundary, TOA spectral radiances are only weakly affected by the presence of water vapor absorption bands. A visual inspection of Figure 2 clearly reveals that the effects of these absorption bands are much smaller over DCC than over desert. The relative uncertainty is pretty wavelength independent and in the range of 2 to $4 \%$. Below $0.9 \mu \mathrm{m}$, the total uncertainty is dominated by COT uncertainty while above this limit, it is dominated by the uncertainty on the ice particle effective radius. 


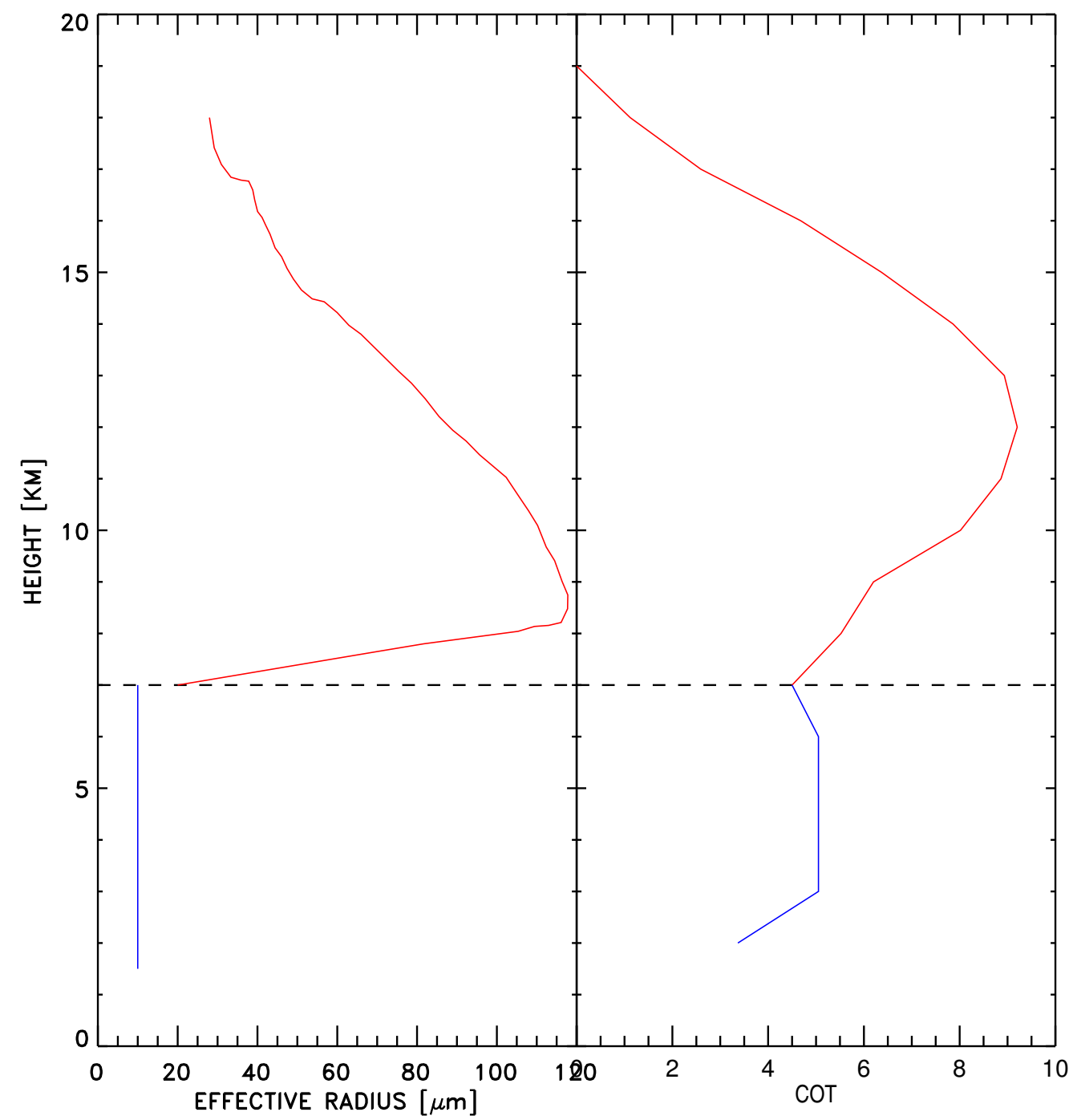

Figure 4. DCC effective radius and cloud optical thickness vertical profile after [27]. Ice crystals are shown in red and water droplet in blue.

\section{TOA Radiance Simulation Accuracy Evaluation}

\subsection{TOA BRF Analysis}

SRF retrieval is possible only if simulated TOA radiances $L\left(\Omega, \lambda, t, l ; q_{j}\right)$ are accurate (Section 2). An independent evaluation of $L\left(\Omega, \lambda, t, l ; q_{j}\right)$ accuracy is therefore critical. This assessment relies on a two-fold approach. The first step addressed in this section focuses on the TOA Bidirectional Reflectance Factor (BRF) analysis over Libya-4. Many observations were acquired over this site by well-calibrated radiometers such as Landsat-8/OLI, AQUA/MODIS, Envisat/MEdium Resolution Imaging Spectrometer (MERIS) and Sentinel-2/MSI which radiometric accuracy is better than $3 \%[4,34,35]$. Data acquired by these instruments were simulated accounting for the actual geometry of illumination and observation as well as the pre-launch SRF of each simulated band. The selected spectral bands of these instruments cover the $0.4-1.0 \mu \mathrm{m}$ spectral region. Only the 1.0-1.2 $\mu \mathrm{m}$ spectral range is not covered. As can be seen in Figure 1, the magnitude of the silicon response beyond $1.1 \mu \mathrm{m}$ is not expected to be very important. Hence, most of the incoming radiance in the MVIRI/VIS band is well captured by these selected spectral bands. 
For each instrument, time series composed of several tens of TOA BRF values $R_{0}\left(\Omega_{0}, t\right)$ where $\Omega_{0}$ represents the acquisition geometry were accumulated (Table 2 ). The corresponding spectral radiance $L\left(\Omega_{0}, \lambda, t, l ; q_{j}\right)$ of each observation was simulated with the LibRadTran RTM as described in Section 4.2. Simulated TOA BRF $R_{S}$ is defined as

$$
\tilde{R}_{s}=\frac{1}{\pi} \frac{d_{\odot}^{2} \int_{\lambda} L\left(\Omega_{0}, \lambda, t, l ; q_{j}\right) \phi_{p}(\lambda) \mathrm{d} \lambda}{\int_{\lambda} I_{0}(\lambda) \phi_{p}(\lambda) \mathrm{d} \lambda \cos \left(\theta_{0}\right)}
$$

where $I_{0}(\lambda)$ the exoatmospheric irradiance spectrum, $\phi_{p}$ is the pre-launch SRF of the simulated band. The mean relative bias between $\tilde{R}_{s}$ and $R_{o}$ is shown in Figure 5 .

Table 2. Number of observations acquired over Libya-4 by each processed instrument: MODIS, MEdium Resolution Imaging Spectrometer (MERIS), Multispectral Instrument (MSI), Operational Land Imager (OLI).

\begin{tabular}{cccc}
\hline Platform & Radiometer & Version & Nbr. of Obs. \\
\hline AQUA & MODIS & Collection 5 & 859 \\
Envisat & MERIS & Third Reprocessing & 865 \\
Sentinel-2 & MSI & Baseline 02.07 & 60 \\
Landsat-8 & OLI & Collection 1 & 54 \\
\hline
\end{tabular}

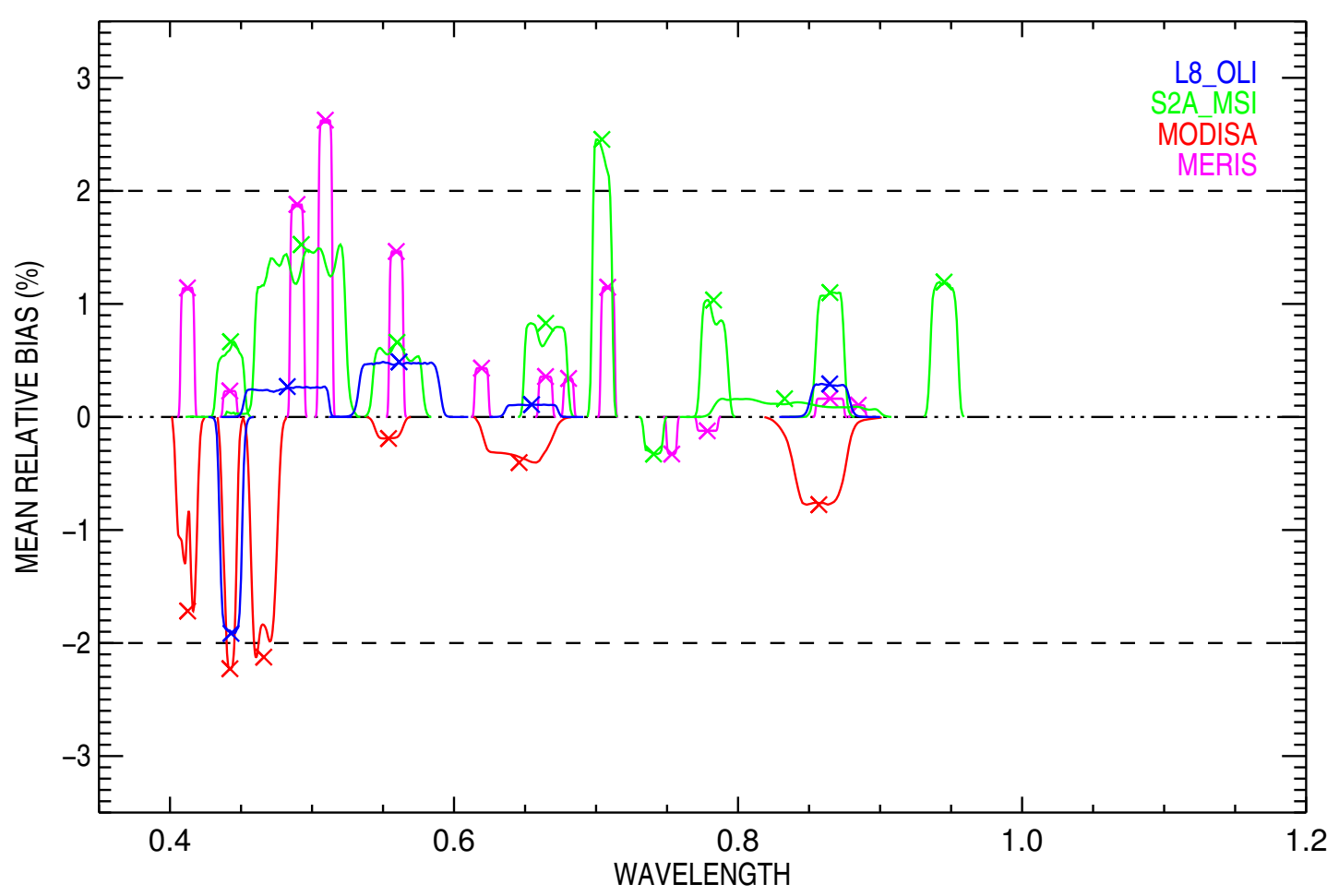

Figure 5. TOA BRF mean relative bias between observation and simulation over Libya-4. The spectral range of each simulated band is represented by the shape of its SRF and the magnitude of the bias by the $\times$ symbol. The maximum of the SRF shape is scaled to this value. The following color code is used: Landsat-8/OLI (blue), Sentinel-2A/MSI (green), Aqua/MODIS (red), Envisat/MERIS (magenta). Wavelength is expressed in $\mu \mathrm{m}$.

The maximum mean relative bias does not exceed $\pm 2.5 \%$, i.e., the calibration accuracy of these instruments. Largest discrepancies between $\tilde{R}_{S}$ and $R_{o}$ occurs in the $0.40-0.55 \mu \mathrm{m}$ spectral interval where simulated TOA BRF $\tilde{R}_{S}$ overestimate MODIS observations by about 1 to $2 \%$ and underestimate 
MERIS observations in the red spectral region by about $2 \%$. Above $0.6 \mu \mathrm{m}$, the mean relative bias between observations and simulations hardly exceed $1 \%$. The standard deviation of the relative bias is displayed in Figure 6. Once again, largest values are observed in the $0.40-0.55 \mu \mathrm{m}$ spectral region to the exception of Sentinel-2A/MSI band S9 centered at $0.945 \mu \mathrm{m}$ dedicated to water vapor total column retrieval. As can be seen in Figure 1, this spectral region is dominated by important water vapor absorption bands. The mean relative bias in that spectral band is about $1 \%$, but its standard deviation is as large as $22 \%$. It indicates that the processing of many observations is needed to minimize the impact of the water vapor profile uncertainty on the simulated spectral radiance in that spectral region.

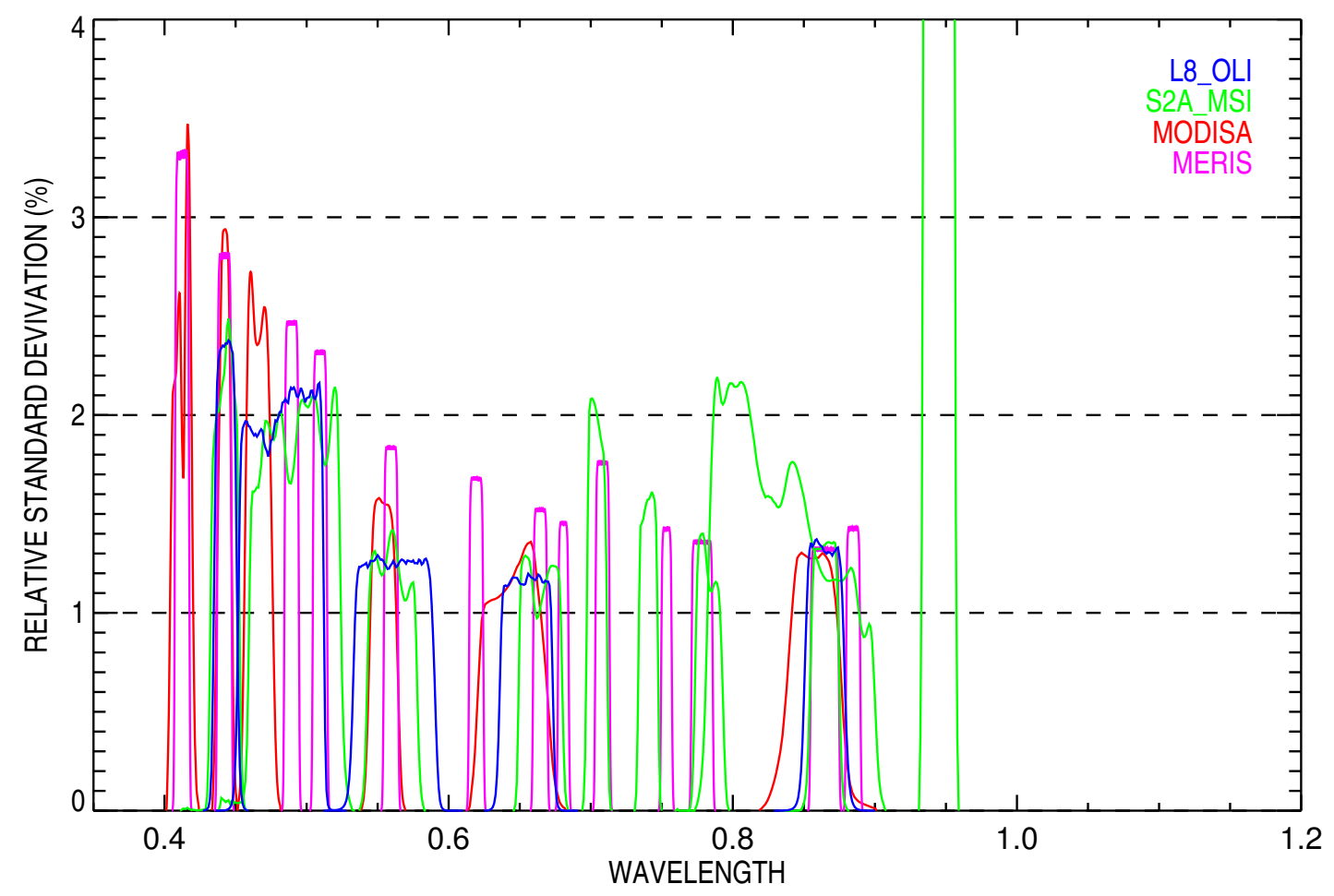

Figure 6. Same as Figure 5 but for the standard deviation of the relative bias.

\subsection{Spectral Consistency across Targets}

In Section 5.1 it is demonstrated that, on average, simulated TOA BRF are accurate within $\pm 2 \%$ or less over Libya- 4 when compared to well-calibrated instruments. In this second accuracy evaluation step, the consistency of the simulated spectral radiance over the three different target types is assessed. This aspect is also important as any discrepancies between the simulated spectrum over the different target types would lead to erroneous SRF retrieval. Assuming that all $L\left(\Omega_{0}, \lambda, t, l ; q_{j}\right)$ spectrum are accurately simulated and the radiometer response to intensity linear, all the couples of points defined by the DC value and the corresponding convoluted radiance

$$
\tilde{L}=\frac{\int_{\lambda} L\left(\Omega_{0}, \lambda, t, l ; q_{j}\right) \phi_{p}(\lambda) \mathrm{d} \lambda}{\int_{\lambda} \phi_{p}(\lambda) \mathrm{d} \lambda}
$$

should fall on a straight line the slope of which is equal to the calibration coefficient and DC axis intercept the estimated space count value $\hat{C}_{0}$ [36]. In case of error free estimation of $\tilde{L}$ and a perfectly linear radiometer behavior, the retrieved slope should be equal to the mean calibration coefficient calculated with Equation (1). This method was applied on the HRVIS band of MSG/SEVIRI instrument which has a reliable pre-launch SRF characterization and a linear response to intensity. For the other SEVIRI radiometers, the HRVIS band was measured only between 0.60 and $0.90 \mu \mathrm{m}$ and extrapolated 
outside this interval with a simple polynomial fitting [37]. Data acquired in 2013 have been used for this experiment.

Results are shown in Figure 7 (left panel) and Table 3. The HRVIS band retrieved offset value $\hat{C}_{0}$ is 49.8 which only differs by $2.4 \%$ or about $1 \mathrm{DC}$ value from the measured one (51.06). The slope of the regression, i.e., the calibration coefficient, is equal to $0.656 \mathrm{Wm}^{-2} \mathrm{sr}^{-1} \mu \mathrm{m}^{-1}$ which is very consistent with the $a$ value of $0.658 \mathrm{Wm}^{-2} \mathrm{sr}^{-1} \mu \mathrm{m}^{-1}$ calculated with Equation (1) and averaged over all couple of points $(C, \tilde{L})$. Table 4 shows the mean $a$ value derived over each type of target for MSG-3. The differences between the calibration coefficients averaged over the various PICS do not exceed $1 \%$. These results confirmed that, on average, the simulated spectral radiances are accurate within $\pm 2 \%$ and very consistent over the 3 PICS types.
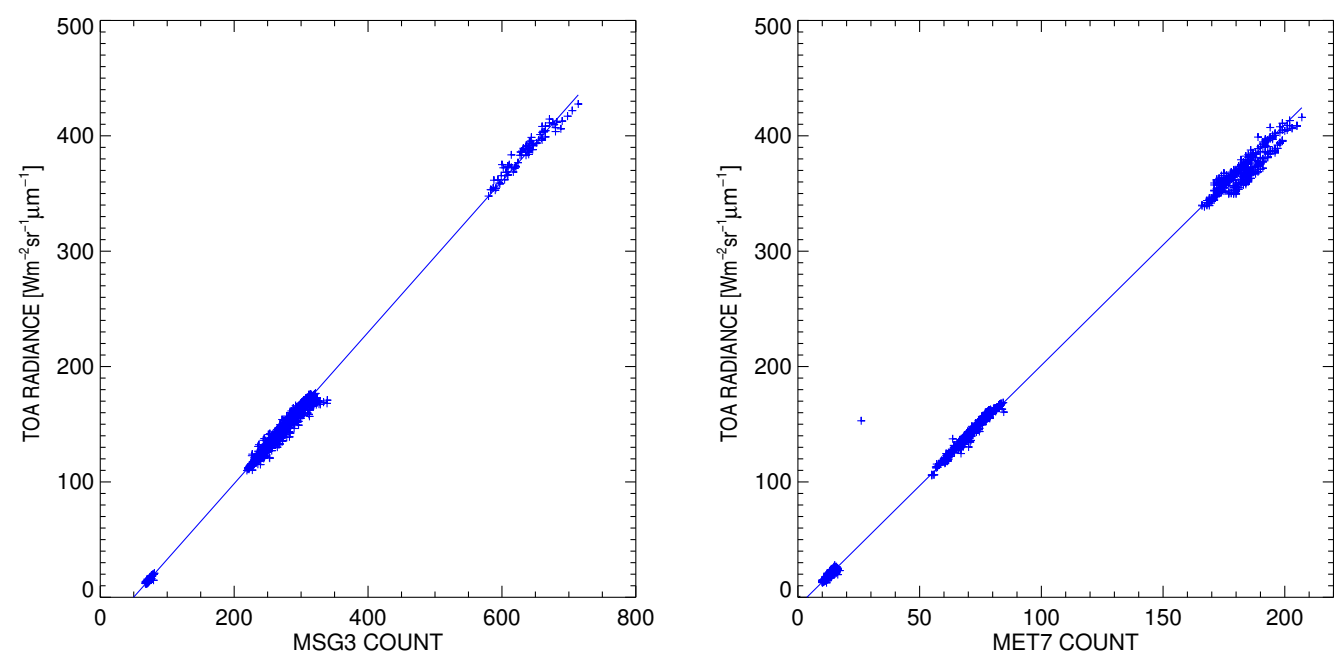

Figure 7. Scatter plot of the DC values and spectral radiances $L$ over the three target types convoluted in MSG-3/SEVIRI/HRVIS (left panel) and Met-7/MVIRI/VIS (right panel) bands.

Table 3. Results of the spectral consistency evaluation. $a$ is expressed in $\mathrm{Wm}^{-2} \mathrm{sr}^{-1} \mu \mathrm{m}^{-1}$.

\begin{tabular}{lcccccccc}
\hline Band & $\boldsymbol{a}$ & $\boldsymbol{u}(\boldsymbol{a})$ & Slope & Slope Uncert. & $\hat{\boldsymbol{C}}_{\mathbf{0}}$ & $\boldsymbol{u}\left(\hat{\boldsymbol{C}}_{\mathbf{0}}\right)$ & $\boldsymbol{C}_{\mathbf{0}}$ & $\boldsymbol{u}\left(\boldsymbol{C}_{\mathbf{0}}\right)$ \\
\hline MSG-3/SEVIRI/HRVIS & 0.658 & 0.017 & 0.656 & 0.003 & 49.81 & 0.924 & 51.06 & 0.252 \\
MET-7/MVIRI/VIS & 2.242 & 0.226 & 2.090 & 0.011 & 3.68 & 0.096 & 4.87 & 0.120 \\
\hline
\end{tabular}

Table 4. Mean calibration coefficient expressed in $\mathrm{Wm}^{-2} \mathrm{sr}^{-1} \mu \mathrm{m}^{-1}$ derived over each target type in 2013 for the MSG-3/SEVIRI/HRVIS band and 2005 for the MET-7/MVIRI/VIS band. Nbr is the number of processed observations.

\begin{tabular}{lcccccc}
\hline \multicolumn{3}{c}{ HRVIS } & \multicolumn{3}{c}{ VIS } \\
\hline Target & Nbr & $\boldsymbol{a}$ & $\boldsymbol{u}(\boldsymbol{a})$ & Nbr & $\boldsymbol{a}$ & $\boldsymbol{u}(\boldsymbol{a})$ \\
\hline Sea & 564 & 0.659 & 0.040 & 661 & 2.424 & 0.180 \\
Desert & 813 & 0.658 & 0.015 & 670 & 2.167 & 0.212 \\
DCC & 214 & 0.661 & 0.013 & 421 & 2.079 & 0.040 \\
\hline All & 1591 & 0.658 & 0.017 & 1752 & 2.242 & 0.226 \\
\hline
\end{tabular}

A similar verification was performed on observations acquired in 2005 by the MVIRI/VIS detectors on board Meteosat-7 using the pre-launch SRF. Result consistency is quite different from those derived with MSG-3 data. Mean $a$ value derived over sea (DCC) over(under)estimates by about $+8 \%(-7 \%)$ the one derived over desert (Table 4). Consequently, the regression slope value (2.090) significantly differs from the mean $a$ value (2.242) derived over all target types (Table 3). However, it should be stressed that uncertainty in the SRF characterization might not be the only factor that could explain 
result discrepancies. The impact of the much lower radiometric performance of MVIRI coded on 8 bits than SEVIRI coded on 10 bits, could also play an important role in the erroneous identification of the PICS targets. For instance, DCC identification highly relies on the thermal band used for the test on DCC top temperature. Similarly, cloud screening used over sea and desert is much more reliable with SEVIRI than MVIRI due to the larger number of spectral bands of the former radiometer used for cloud detection.

\section{Conclusions}

Past attempts to produce CDRs from MVIRI/VIS band observations have revealed the need to rely on a consistent and accurate FCDR. The lack of accurate pre-launch SRF characterization and its ageing constitute a serious limitation to achieve this objective. The FIDUCEO project main objective is to address these types of limitations. This paper presents an important aspect of the efforts undertaken to generate a consistent FCDR from MVIRI/VIS band observations, namely the generation of reliable TOA radiance spectrum over selected PICSs. The radiative properties of these targets relies on a limited number of parameters that can vary both in space and time, all other parameters such as the atmospheric vertical profiles being kept constant. Uncertainties on these properties are taken into account and propagated into the simulated spectral radiance following the Guide to the Expression of Uncertainty in Measurement.

These TOA spectral radiances were simulated over open ocean, bright desert and DCC for the entire duration of the MFG mission, i.e., from Meteosat-2 data acquired in 1982 to Meteosat-7 data acquired in 2015 to support the MVIRI/VIS band retrieval of these instruments, i.e., the same method is used for the processing of the entire archive. The characterization of all input parameters relies on climate data set with a monthly temporal resolution or are assumed time-invariant. Only meteorological information taken from ECMWF data such as the total column water vapor, ozone or surface wind speed over sea explicitly vary in time. Stratospheric aerosols constitute an exception and fortunately data sets exist to account for these variations. Bright desert surface reflectance, ocean salinity and DCC water droplet/ice crystal radius are assumed invariant because of PICS intrinsic nature. A single radiance spectrum can be simulated with an estimated uncertainty of about $5 \%$.

Significant efforts were dedicated to the independent verification of simulated TOA radiance accuracy. A two-fold approach was followed. First, the accuracy of the simulation over bright desert is estimated against well-calibrated modern instruments. The consistency with simulations over open ocean and DCC is performed in a second step using the SEVIRI/HRVIS band on board MSG-3. This evaluation demonstrated that, on average, the simulated spectral radiance uncertainty can be reduced to about $2 \%$ when many observations are considered. This value is comparable to results obtained by other studies [28,38,39]. A similar verification performed on Meteosat-7 data confirmed the issue with the characterization of the MVIRI/VIS band SRF. The outcome of this paper is a key result for the reconstruction of the in-flight SRF and the recalibration of MVIRI data described in companion papers $[6,16]$.

Author Contributions: Y.M.G. wrote this article. He developed the method for DCC pixel identification and performed the TOA radiance simulation and validation. F.R. carried out the pixel extraction over bright desert and open ocean with the SSCC algorithm. V.O.J. developed the MVIRI/IR band calibration method used for DCC identification. R.Q. contributed to the elaboration of the spectral radiance generation requirements.

Funding: This research was funded by European Union Horizon 2020 Programme for Research and Innovation grant number 638822.

Conflicts of Interest: The authors declare no conflict of interest. 


\section{Abbreviations}

The following abbreviations are used in this manuscript:

\begin{tabular}{|c|c|}
\hline AOT & Aerosol Optical Thickness \\
\hline BIPM & Bureau International des Poids et Mesures (International Bureau of Weights and Measures) \\
\hline BRF & Bidirectional Reflectance Factor \\
\hline CDR & Climate Data Record \\
\hline CEOS & Committee on Earth Observation Satellites \\
\hline CGMS & Coordination Group for Meteorological Satellites \\
\hline COT & Cloud Optical Thickness \\
\hline DC & Digital Count \\
\hline DCC & Deep Convective Cloud \\
\hline ECMWF & European Centre for Medium-Range Weather Forecasts \\
\hline FCDR & Fundamental Climate Data Record \\
\hline FIDUCEO & Fidelity and Uncertainty in Climate Data Records from Earth Observation \\
\hline HRVIS & High Resolution VISible \\
\hline INDOEX & INDian Ocean EXperiment \\
\hline IODC & Indian Ocean Data Coverage \\
\hline IR & InfraRed \\
\hline MFG & Meteosat First Generation \\
\hline MERIS & MEdium Resolution Imaging Spectrometer \\
\hline MODIS & MOderate Resolution Imaging Spectroradiometer \\
\hline MSG & Meteosat Second Generation \\
\hline MSI & Multi-Spectral Instrument \\
\hline MVIRI & Meteosat Visible and InfraRed Imaged \\
\hline OLI & Operational Land Imager \\
\hline PICS & Pseudo-Invariant Calibration Site \\
\hline RTM & Radiative Transfer Model \\
\hline SEVIRI & Spinning Enhanced Visible and Infrared Imager \\
\hline SI & International System of Units \\
\hline SRF & Sensor Response Function \\
\hline SSCC & SEVIRI Solar Channel Calibration \\
\hline TOA & Top-Of-Atmosphere \\
\hline VIS & VISible \\
\hline ZDM & Zero-Dregree Mission \\
\hline
\end{tabular}

\section{References}

1. Govaerts, Y.M. Correction of the Meteosat-5 and -6 VIS band relative spectral response with Meteosat-7 characteristics. Int. J. Remote Sens. 1999, 20, 3677-3682. [CrossRef]

2. Loew, A.; Govaerts, Y. Towards Multidecadal Consistent Meteosat Surface Albedo Time Series. Remote Sens. 2010, 2, 957-967. [CrossRef]

3. Decoster, I.; Govaerts, Y.M.; Baudrez, E.; Dewitte, S.; Velazquez, A.; Blazquez, A.; Cornelis, J. Evidence of pre-launch characterization problem of Meteosat-7 visible spectral response. Remote Sens. Lett. 2013, 4, 1008-1017. [CrossRef]

4. Xiong, X.; Fulbright, J.; Angal, A.; Wang, Z.; Geng, X.; Butler, J. Assessment of MODIS and VIIRS solar diffuser on-orbit degradation. Proc. SPIE 2015.[CrossRef]

5. Govaerts, M.Y. Exploitation of the Meteosat Archive for climate monitoring: Expectations and limitations. In Proceedings of the 1999 EUMETSAT Meteorological Satellite Data User's Conference, Copenhagen, Denmark, 6-10 September 1999; pp. 255-262.

6. Quast, R.; Giering, R.; Govaerts, Y.M.; Rüthrich, F.; Roebeling, R. Climate Data Records from Meteosat First Generation Part II: Retrieval of the In-Flight Visible Spectral Response. Remote Sens. 2018, in press.

7. Govaerts, Y.M.; Clerici, M.; Clerbaux, N. Operational Calibration of the Meteosat Radiometer VIS Band. IEEE Trans. Geosci. Remote Sens. 2004, 42, 1900-1914. [CrossRef] 
8. Ramanathan, V.; Crutzen, P.J.; Lelieveld, J.; Mitra, A.P.; Althausen, D.; Anderson, J.; Andreae, M.O.; Cantrell, W.; Cass, G.R.; Chung, C.E.; et al. Indian Ocean Experiment: An integrated analysis of the climate forcing and effects of the great Indo-Asian haze. J. Geophys. Res. Atmos. 2001, 106, 28371-28398. [CrossRef]

9. Govaerts, Y.M.; Clerici, M. SEVIRI Solar Channel Calibration-Algorithm Specification Document; Technical Report EUM/MSG/SPE/411, Version 1.2; EUMETSAT: Darmstadt, Germany, 2001.

10. Cosnefroy, H.; Leroy, M.; Briottet, X. Selection and characterization of Saharan and Arabian desert sites for the calibration of optical satellite sensors. Remote Sens. Environ. 1996, 58, 101-114. [CrossRef]

11. Govaerts, Y.M. Operational vicarious calibration of MFG/MVIRI and MSG/SEVIRI solar channels. In Proceedings of the 9th International Symposium on Physical Measurements and Signatures in Remote Sensing, Beijing, China, 17-19 October 2005; Liang, S., Liu, J., Li, X., Liu, R., Schaepman, M., Eds.; ISPRS Working Groups VII/1: Beijing, China, 2005; Volume XXXVI, pp. 446-448.

12. Uppala, S.M.; KÅllberg, P.W.; Simmons, A.J.; Andrae, U.; Bechtold, V.D.C.; Fiorino, M.; Gibson, J.K.; Haseler, J.; Hernandez, A.; Kelly, G.A.; et al. The ERA-40 re-analysis. Q. J. R. Meteorol. Soc. 2005, 131, 2961-3012. [CrossRef]

13. Astruc, P. METEOSAT Transition Programme Imaging Chain: Calibration Data; Technical Report MTP.88.E.318; Eumetsat: Darmstadt, Germany, 1997.

14. Van Dahl, M. MTP CF to INGATE (MPEF) Interface Control Document; Technical Report EUM/TSS/ICD/ 14/778737; EUMETSAT: Darmstadt, Germany, 2016.

15. Wolf, R. LRIT/HRIT Global Specification; Technical Report CGMS 03; CGMS: Geneva, Switzerland, 1999.

16. Reuthrich, F.; Quast, R.; Govaerts, Y.M.; John, V.O.; Roebeling, R.; Wooliams, E.; Schulz, J. Climate Data Records from Meteosat First Generation Part III: Recalibration and Uncertainty Tracing of the Visible channel on METEOSAT 2-7 using Reconstructed, Spectrally Changing Response Functions. Remote Sens. 2018, in press.

17. EUMETSAT. Meteosat First Generation User Handbook; Technical Report EUM/OPS/USR/10/1537; EUMETSAT: Darmstadt, Germany, 2011.

18. Govaerts, Y.M. Sand Dune Ridge Alignment Effects on Surface BRF over the Libya-4 CEOS Calibration Site. Sensors 2015, 15, 3453-3470. [CrossRef]

19. Govaerts, Y.; Sterckx, S.; Adriaensen, S. Use of simulated reflectances over bright desert target as an absolute calibration reference. Remote Sens. Lett. 2013, 523-531. [CrossRef]

20. Baum, A.; Yang, P.; Heymsfield, J.; Bansemer, R.; Cole, H.; Merrelli, A.; Schmitt, G.; Wang, C. Ice cloud single-scattering property models with the full phase matrix at wavelengths from 0.2 to $100 \mu \mathrm{m}$. J. Quant. Spectrosc. Radiat. Transf. 2014, 146, 123-139. [CrossRef]

21. Doelling, D.R.; Morstad, D.; Scarino, B.R.; Bhatt, R.; Gopalan, A. The Characterization of Deep Convective Clouds as an Invariant Calibration Target and as a Visible Calibration Technique. IEEE Trans. Geosci. Remote Sens. 2013, 51, 1147-1159. [CrossRef]

22. BIPM. Evaluation of Measurement Data-Guide to the Expression of the Uncertainty in Measurement. Technical Report JCGM 100:2008 GUM 1995 with Minor Corrections. 2008. Available online: https:/ / ncc. nesdis.noaa.gov/documents / documentation/JCGM_100_2008_E.pdf (accessed on 5 December 2018).

23. Govaerts, Y.M.; Clerici, M. Evaluation of radiative transfer simulations over bright desert calibration sites. IEEE Trans. Geosci. Remote Sens. 2004, 42, 176-187. [CrossRef]

24. Emde, C.; Buras-Schnell, R.; Kylling, A.; Mayer, B.; Gasteiger, J.; Hamann, U.; Kylling, J.; Richter, B.; Pause, C.; Dowling, T.; et al. The libRadtran software package for radiative transfer calculations (version 2.0.1). Geosci. Model Dev. 2016, 9, 1647-1672. [CrossRef]

25. Gasteiger, J.; Emde, C.; Mayer, B.; Buras, R.; Buehler, S.A.; Lemke, O. Representative wavelengths absorption parameterization applied to satellite channels and spectral bands. J. Quant. Spectrosc. Radiat. Transf. 2014, 148, 99-115. [CrossRef]

26. Dee, D.P.; Uppala, S.M.; Simmons, A.J.; Berrisford, P.; Poli, P.; Kobayashi, S.; Andrae, U.; Balmaseda, M.A.; Balsamo, G.; Bauer, P.; et al. The ERA-Interim reanalysis: Configuration and performance of the data assimilation system. Q. J. R. Meteorol. Soc. 2011, 137, 553-597. [CrossRef]

27. Sohn, B.J.; Choi, M.J.; Ryu, J. Explaining darker deep convective clouds over the western Pacific than over tropical continental convective regions. Atmos. Meas. Tech. 2015, 8, 4573-4585. [CrossRef] 
28. Sterckx, S.; Livens, S.; Adriaensen, S. Rayleigh, Deep Convective Clouds, and Cross-Sensor Desert Vicarious Calibration Validation for the PROBA-V Mission. IEEE Trans. Geosci. Remote Sens. 2013, 51, 1437-1452. [CrossRef]

29. Cox, C.; Munk, W. Measurement of the Roughness of the Sea Surface from Photographs of the Sun's Glitter. J. Opt. Soc. Am. 1954, 44, 838-850. [CrossRef]

30. Shettle, E.P.; Fenn, R.W. Models for the Aerosols of the Lower Atmosphere and the Effects of Humidity Variations on Their Optical Properties. 1979. Available online: http://web.gps.caltech.edu/ vijay/Papers/ Aerosol/SF79-Aerosol-Models-part1of4.PDF (accessed on 5 December 2018).

31. Russell, P.B.; Livingston, J.M.; Pueschel, R.F.; Bauman, J.J.; Pollack, J.B.; Brooks, S.L.; Hamill, P.; Thomason, L.W.; Stowe, L.L.; Deshler, T.; et al. Global to microscale evolution of the Pinatubo volcanic aerosol derived from diverse measurements and analyses. J. Geophys. Res. 1996, 101, 18745-18764. [CrossRef]

32. Vernier, J.P.; Thomason, L.W.; Pommereau, J.P.; Bourassa, A.; Pelon, J.; Garnier, A.; Hauchecorne, A.; Blanot, L.; Trepte, C.; Degenstein, D.; et al. Major influence of tropical volcanic eruptions on the stratospheric aerosol layer during the last decade. Geophys. Res. Lett. 2011, 38. [CrossRef]

33. Thomason, L. SAGE II Stratospheric Aerosol Data Products; Technical Report; NASA Langley Atmospheric Science Data Center: Hampton, VA, USA, 1998.

34. Delwart, S.; Preusker, R.; Bourg, L.; Santer, R.; Ramon, D.; Fischer, J. MERIS inflight spectral calibration. Int. J. Remote Sens. 2007, 28, 479-496. [CrossRef]

35. Gascon, F.; Bouzinac, C.; Thépaut, O.; Jung, M.; Francesconi, B.; Louis, J.; Lonjou, V.; Lafrance, B.; Massera, S.; Gaudel-Vacaresse, A.; et al. Copernicus Sentinel-2A Calibration and Products Validation Status. Remote Sens. 2017, 9, 584. [CrossRef]

36. Govaerts, Y.M.; Arriaga, A.; Schmetz, J. Operational Vicarious Calibration of the MSG/SEVIRI Solar Channels. Adv. Space Res. 2001, 28, 21-30. [CrossRef]

37. Govaerts, Y.M. Impact of the SEVIRI HRV Spectral Response Characterisation on the Effective Radiance Estimation; Technical Report MET/MEM/99.015; EUMETSAT: Darmstadt, Germany, 1999.

38. Chen, W.; Zhao, H.; Li, Z.; Jing, X.; Yan, L. Uncertainty Evaluation of an In-Flight Absolute Radiometric Calibration Using a Statistical Monte Carlo Method. IEEE Trans. Geosci. Remote Sens. 2015, 53, 2925-2934. [CrossRef]

39. Mishra, N.; Helder, D.; Angal, A.; Choi, J.; Xiong, X. Absolute Calibration of Optical Satellite Sensors Using Libya 4 Pseudo Invariant Calibration Site. Remote Sens. 2014, 6, 1327-1346. [CrossRef]

(C) 2018 by the authors. Licensee MDPI, Basel, Switzerland. This article is an open access article distributed under the terms and conditions of the Creative Commons Attribution (CC BY) license (http:/ / creativecommons.org/licenses/by/4.0/). 